\title{
Incidence of periodontal compromise in teeth indicated for undergoing endodontic treatment: A clinical study
}

\author{
Ricardo Machado ${ }^{1}$, Monique Muniz da Cunha ${ }^{2}$, Daniel Comparin ${ }^{3}$, Leopoldo Cosme-Silva ${ }^{4}$, \\ Eduardo Donato Eing Engelke Back ${ }^{5}$, Lucas da Fonseca Roberti Garcia ${ }^{6}$
}

Correspondence: Dr. Ricardo Machado

Email: ricardo.machado.endo@gmail.com

\author{
'Clinical Practice Limited to Endodontics, Navegantes, \\ Santa Catarina, Brazil, \\ 2Private Clinical Practice, Blumenau, Santa Catarina, \\ Brazil, \\ ${ }^{3}$ Clinical Practice Limited to Endodontics, Cunha Porã, \\ Santa Catarina, Brazil, \\ ${ }^{4}$ Department of Endodontics, State University of São \\ Paulo, Araçatuba, São Paulo, Brazil, \\ ${ }^{5}$ Private Clinical Practice, Joinville, Santa Catarina, \\ Brazil, \\ ${ }^{6}$ Department of Dentistry, Division of Endodontics, \\ Health Sciences Center, Federal University of Santa \\ Catarina, Florianópolis, Santa Catarina, Brazil
}

\section{ABSTRACT}

Objective: The aim of this study was to evaluate the periodontal status of teeth indicated for undergoing endodontic treatment. Materials and Methods: Two hundred and nine teeth were evaluated using probing depth tests at three vestibular and three palatine/lingual sites before the patients underwent treatment. Teeth that presented up to 3-mm probing depth were considered as healthy. Those that presented at least one site with probing depth $>3 \mathrm{~mm}$ were considered periodontally compromised. The data were statistically analyzed by means of applying the Chi-square test, with a level of significance of $5 \%$. Results: Of the total of 209 teeth evaluated, 40 (19.10\%) presented periodontal compromise. There was statistically significant difference related to the compromised teeth of patients of the female gender $(22.80 \%)$ compared with teeth of patients of the male gender $(12.30 \%)(P<0.05)$. Conclusions: Fewer than $20 \%$ of the teeth evaluated presented a periodontal compromise. Patients of the female gender presented a higher number of periodontally compromised teeth than patients of the male gender.

Key words: Endodontic treatment, periodontal disease, probing depth

\section{INTRODUCTION}

Endodontics is one of the dental specialties that has presented most changes in the way its treatment is performed by the technical and scientific advances that have occurred over the past few decades. ${ }^{[1-4]}$

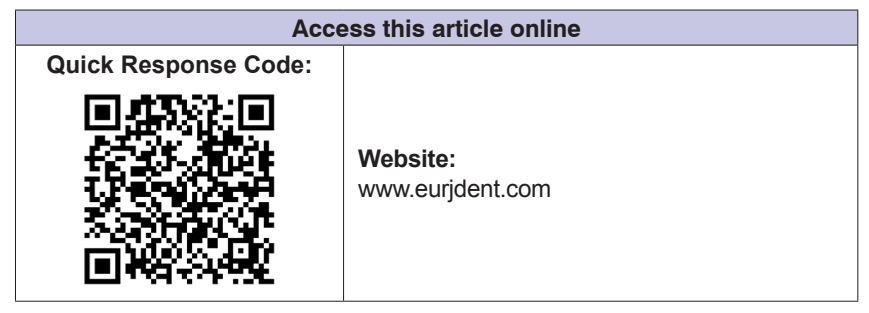

Nevertheless, maintaining endodontically treated in the oral cavity for a long period continues to represent a great challenge..$^{[5-8]}$

This is an open access journal, and articles are distributed under the terms of the Creative Commons Attribution-NonCommercial-ShareAlike 4.0 License, which allows others to remix, tweak, and build upon the work non-commercially, as long as appropriate credit is given and the new creations are licensed under the identical terms.

For reprints contact: reprints@medknow.com

How to cite this article: Machado $R$, da Cunha MM, Comparin D, Cosme-Silva L, Engelke Back ED, Roberti Garcia Ld. Incidence of periodontal compromise in teeth indicated for undergoing endodontic treatment: A clinical study. Eur J Dent 2018;12:334-7.

DOI: 10.4103/ejd.ejd_271_17 
Among the main reasons associated with the loss of endodontically treated teeth, periodontal diseases frequently appear as one of the most relevant types. ${ }^{[9-11]}$ However, strangely enough, there is limited scientific evidence about the importance of periodontal status in relation to successful endodontic treatment and maintenance of endodontically treated teeth in the long term. ${ }^{[11,12]}$

Therefore, the aim of this study was to evaluate the incidence of periodontal compromise in teeth indicated for undergoing endodontic treatment.

\section{MATERIALS AND METHODS}

\section{Sample size calculation}

To obtain the minimum number of teeth to be evaluated in this study, the following formula was used: ${ }^{[13,14]}$

$$
n=\frac{\frac{t^{2} \cdot P \cdot(1-P)}{d^{2}}}{1+\frac{1}{N} \times\left(\frac{t^{2} \cdot P \cdot(1-P)}{d^{2}}-1\right)}
$$

Where:

- $N$ : Size of the target population. According to data from the Brazilian Institute of Geography and Statistics, ${ }^{[15]}$ at the time of conducting the research, the population of the State of Santa Catarina, Brazil (where data were collected), was 6.8 million persons.

- $n$ : size of desired sample.

- $t$ : Abscissa of the normal curve determined by an area of size a (alpha), which is the calculated risk, so that the maximum margin of error adopted would be as low as possible; in this case, $t=1.96$.

- $d$ : Maximum margin of error adopted, or also called the precision adopted; values between 1\% and $20 \%$ could be adopted; the value 5\% (margin of error), whose precision was thus equivalent to $95 \%$ was one of the most usual values.

- P: Proportion of occurrence of the fact observed. When the population value is previously unknown, the population value, $P=50 \%(0.5000)$ is adopted), which allows maximization of the value of ' $n$ '; in this case, the value of $9.6 \%$ was adopted, which was the information coming from the National Oral Health Survey of 2010. ${ }^{[16]}$

Therefore, by substituting the values adopted, a minimum number of 134 teeth was obtained [Table 1].

\section{Clinical procedures}

This research was conducted in accordance with the principles of the Helsinki Declaration, and all the participants or their legal guardians signed the long term of free and informed consent, authorizing the treatment to be performed and disclosure of its results. Thus, 209 teeth of 209 patients with ages ranging from 31 to 40 years with endodontic treatment needs were evaluated by means of probing depth tests at three vestibular and three palatine/lingual sites, performed by a single operator during clinical activities of the specialization course in Endodontics of the Hermann Blumenau Institute between October 2014 and August 2015. Teeth that presented up to 3-mm probing depth were considered healthy. Those that presented at least one site with probing depth $>3 \mathrm{~mm}$ were considered compromised. Teeth associated with suspected cracks or root fractures were excluded from the analysis.

\section{Statistical analysis}

The data obtained were statistically analyzed using applying the Chi-square test, with a level of significance of $5 \%$. All data were analyzed using the SPSS statistical program (SPSS Inc., Chicago, IL, USA).

\begin{tabular}{ccccccc}
\multicolumn{6}{l}{ Table 1: Summary of sample size calculation } \\
\hline $\boldsymbol{t}$ & $\boldsymbol{t}^{2}$ & $\boldsymbol{P}$ & $\boldsymbol{1}-\boldsymbol{P}$ & $\boldsymbol{d}$ & $\boldsymbol{d}^{\mathbf{2}}$ & $\boldsymbol{n}$ \\
\hline 1.96 & 3.8416 & 0.0960 & 0.9040 & 0.05 & 0.0025 & 134 \\
\hline
\end{tabular}

\begin{tabular}{lccc}
$\begin{array}{l}\text { Table 2: Number of teeth evaluated in the study, by } \\
\text { gender }\end{array}$ & $\begin{array}{c}\text { Patients } \\
\text { of male } \\
\text { gender }(\boldsymbol{n})\end{array}$ & $\begin{array}{c}\text { Patients } \\
\text { of female } \\
\text { gender }(\boldsymbol{n})\end{array}$ & Total \\
\hline Tooth treated & 5 & 7 & 12 \\
\hline Maxillary central incisor & 8 & 8 & 16 \\
Maxillary lateral incisor & 4 & 11 & 15 \\
Maxillary canine & 6 & 16 & 22 \\
Maxillary first premolar & 7 & 11 & 18 \\
Maxillary second premolar & 6 & 17 & 23 \\
Maxillary first molar & 4 & 6 & 10 \\
Maxillary second molar & 0 & 1 & 1 \\
Maxillary third molar & 2 & 1 & 3 \\
Mandibular central incisor & 1 & 2 & 3 \\
Mandibular lateral incisor & 0 & 1 & 1 \\
Mandibular canine & 4 & 7 & 11 \\
Mandibular first premolar & 7 & 8 & 15 \\
Mandibular second premolar & 14 & 25 & 39 \\
Mandibular first molar & 5 & 14 & 19 \\
Mandibular second molar & 0 & 1 & 1 \\
Mandibular third molar & 73 & 136 & 209 \\
Total & &
\end{tabular}




\section{RESULTS}

The general list of teeth treated and their distribution, considering gender may be viewed in [Table 2].

Of the total of 209 teeth evaluated, 40 (19.10\%) presented periodontal compromise (probing depth $>3 \mathrm{~mm}$ in at least one site analyzed). Statistically significant difference was found relative to a number of compromised teeth of patients of the female $(22.80 \%)$ and male $(12.30 \%)$ gender $(P=0.04)$ [Table 3].

When the position of the teeth in the arch was compared, the number of compromised anterior teeth was similar to the number found for posterior teeth $(18 \%$ and $19.5 \%$, respectively) $(P=0.81)$ [Table 4].

In patients of the female gender, the proportion of compromised anterior teeth was higher $(27.7 \%)$ than that in patients of the male gender $(5.0 \%)$ $(P=0.03)$ [Table 5].

When the same analysis was made for the posterior teeth, the number of compromised teeth in patients of the female gender was also higher $(21.7 \%)$ compared with that found in patients of the male gender (15.1\%). However, there was no statistically significant difference $(P=0.31)$ [Table 6].

\section{DISCUSSION}

There is little scientific evidence that associates successful endodontic treatment with the maintenance of these teeth in the oral cavity in the long term. ${ }^{[1,12]}$ Considering that periodontal diseases frequently appear as one of the main factors associated with the loss of endodontically treated teeth, ${ }^{[9-11]}$ the aim of this study was to evaluate the incidence of periodontal compromise in teeth indicated for undergoing endodontic treatment.

The general results obtained revealed that only a small number of teeth $(19.10 \%)$ presented a probing depth $>3 \mathrm{~mm}$ in at least one of the sites evaluated; However, a significantly higher number of compromised teeth were observed in patients of the female gender $(22.80 \%)$ compared with the teeth in patients of the male gender $(12.30 \%)$. These results were contrary to those observed in the majority of studies previously conducted, in which higher rates of periodontal compromise were observed in patients of the male gender ${ }^{[5-7]}$ This may be associated with the substantial difference in the number of patients per

\begin{tabular}{cccc}
$\begin{array}{l}\text { Table 3: General analysis of periodontally } \\
\text { compromised teeth considering patients' gender }\end{array}$ \\
$\begin{array}{cccc}\text { Periodontal } \\
\text { status }\end{array}$ & $\begin{array}{c}\text { Patients of } \\
\text { male gender, } \\
\boldsymbol{n}(\%)\end{array}$ & $\begin{array}{c}\text { Patients } \\
\text { of female } \\
\text { gender, } \boldsymbol{n}(\%)\end{array}$ & $\begin{array}{c}\text { Total, } \\
\boldsymbol{n}(\%)\end{array}$ \\
\hline Healthy teeth & $64(87.70)$ & $105(77.20)$ & $169(80.90)$ \\
Compromised teeth & $9(12.30)$ & $31(22.80)$ & $40(19.10)$ \\
Total & $73(100)$ & $136(100)$ & $209(100)$ \\
\hline$P=0.04$ & & &
\end{tabular}

\begin{tabular}{|c|c|c|c|}
\hline Periodontal status & $\begin{array}{c}\text { Anterior } \\
\text { teeth, } n(\%)\end{array}$ & $\begin{array}{c}\text { Posterior } \\
\text { teeth, } \boldsymbol{n}(\%)\end{array}$ & $\begin{array}{l}\text { Total, } \\
n(\%) \\
\end{array}$ \\
\hline Healthy patients & $41(82)$ & $128(80.5)$ & $169(80.9)$ \\
\hline Compromised patients & $9(18)$ & $31(19.5)$ & $40(19.1)$ \\
\hline Total & $50(100)$ & $159(100)$ & $209(100)$ \\
\hline
\end{tabular}

\begin{tabular}{|c|c|c|c|}
\hline $\begin{array}{l}\text { Periodontal } \\
\text { status }\end{array}$ & $\begin{array}{c}\text { Patients of } \\
\text { male gender, } \\
n(\%)\end{array}$ & $\begin{array}{c}\text { Patients } \\
\text { of female } \\
\text { gender, } n(\%)\end{array}$ & $\begin{array}{l}\text { Total, } \\
n(\%)\end{array}$ \\
\hline Healthy teeth & $19(95)$ & $22(73.3)$ & $41(82)$ \\
\hline Compromised teeth & $1(5)$ & $8(27.7)$ & $9(18)$ \\
\hline Total & $20(100)$ & $30(100)$ & $50(100)$ \\
\hline
\end{tabular}

\begin{tabular}{|c|c|c|c|}
\hline $\begin{array}{l}\text { Periodontal } \\
\text { status }\end{array}$ & $\begin{array}{l}\text { Patients of } \\
\text { male gender, } \\
n(\%)\end{array}$ & $\begin{array}{c}\text { Patients } \\
\text { of female } \\
\text { gender, } n(\%)\end{array}$ & $\begin{array}{l}\text { Total, } \\
n(\%)\end{array}$ \\
\hline Healthy teeth & $45(84.9)$ & $83(78.3)$ & $128(80.5$ \\
\hline Compromised teeth & $8(15.1)$ & $23(21.7)$ & $31(19.5)$ \\
\hline Total & $53(100)$ & $106(100)$ & $159(100)$ \\
\hline
\end{tabular}

gender evaluated in this study (136 teeth of female patients and 73 teeth of male patients). Moreover, there are scientific evidence showing different rates of periodontal diseases in patients of different age-ranges and with systemic compromise, such as diabetes, obesity, and cardiovascular diseases. ${ }^{[17]}$ In the present study, these extrinsic factors were not compared, taking into consideration the gender of patients, representing a limitation about interpreting the results.

Irrespective of gender, when the position of the teeth in the arch was compared, the number of compromised anterior teeth was similar to the number found for posterior teeth (18\% and $19.5 \%$, respectively). These 
results were associated with the fact that periodontal compromise frequently occurred in a generalized manner in the dental arch. As previously observed, the patients who presented a probing depth $>3 \mathrm{~mm}$ in at least one site of the tooth referred for undergoing endodontic treatment, probably also presented more compromised teeth. ${ }^{[17,18]}$

In this research, only observational data were obtained about the presence of periodontal pockets in teeth referred for undergoing endodontic treatment. In a study with a broader scope, Skupien et al. ${ }^{[11]}$ investigated the success rate and maintenance of endodontically treated and restored teeth, and correlated these variables with periodontal data. Of the 360 teeth evaluated for the mean period of 4.34 years, 19 teeth were extracted and 27 restorations required repair or replacement. Moreover, the authors observed that the increase in probing depth resulted in a significant increase in the risk of loss of the treated tooth. These results ratified the importance of correct periodontal examination to be performed by the endodontist. For this reason, further multicentric studies are necessary, with methodological designs similar to that of the present study; however, with a larger number of samples and more extensive periodontal analyses, to identifying other risk factors that could contribute to the loss of endodontically treated teeth.

\section{CONCLUSIONS}

According to the data observed in this study, fewer than $20 \%$ of teeth referred for undergoing endodontic treatment presented a periodontal compromise. Patients of the female gender presented a higher number of periodontally compromised teeth in comparison with patients of the male gender.

\section{Financial support and sponsorship}

Nil.

\section{Conflicts of interest}

There are no conflicts of interest.

\section{REFERENCES}

1. Fox RZ. Endodontics: Recapitulation and evolution. CDS Rev 1994;87:10-1.

2. Glassman GD, Serota KS. Endodontics in transition: Evolution of the rotary revolution. Oral Health 1997;87:37-40.

3. Gutmann JL, Gutmann MS. Historical perspectives on the evolution of surgical procedures in endodontics. J Hist Dent 2010;58:1-42.

4. Reid RJ. The evolution of modern endodontics. Aust Endod J 1998;24:57.

5. Chen SC, Chueh LH, Hsiao CK, Tsai MY, Ho SC, Chiang CP, et al. An epidemiologic study of tooth retention after nonsurgical endodontic treatment in a large population in Taiwan. J Endod 2007;33:226-9.

6. Salehrabi R, Rotstein I. Endodontic treatment outcomes in a large patient population in the USA: An epidemiological study. J Endod 2004;30:846-50.

7. Fransson H, Dawson VS, Frisk F, Bjørndal L, EndoReCo, Kvist T, et al. Survival of root-filled teeth in the Swedish adult population. J Endod 2016;42:216-20.

8. Tzimpoulas NE, Alisafis MG, Tzanetakis GN, Kontakiotis EG. A prospective study of the extraction and retention incidence of endodontically treated teeth with uncertain prognosis after endodontic referral. J Endod 2012;38:1326-9.

9. Touré B, Faye B, Kane AW, Lo CM, Niang B, Boucher Y, et al. Analysis of reasons for extraction of endodontically treated teeth: A prospective study. J Endod 2011;37:1512-5.

10. Vire DE. Failure of endodontically treated teeth: Classification and evaluation. J Endod 1991;17:338-42.

11. Skupien JA, Opdam NJ, Winnen R, Bronkhorst EM, Kreulen CM, Pereira-Cenci $\mathrm{T}$, et al. Survival of restored endodontically treated teeth in relation to periodontal status. Braz Dent J 2016;27:37-40.

12. Stassen IG, Hommez GM, De Bruyn H, De Moor RJ. The relation between apical periodontitis and root-filled teeth in patients with periodontal treatment need. Int Endod J 2006;39:299-308.

13. Kim HY. Statistical notes for clinical researchers: Sample size calculation 2. Comparison of two independent proportions. Restor Dent Endod 2016;41:154-6.

14. Tavernier E, Trinquart L, Giraudeau B. Finding alternatives to the dogma of power based sample size calculation: Is a fixed sample size prospective meta-experiment a potential alternative? PLoS One 2016;11:e0158604.

15. Available from: http://www.ibge.gov.br. [Last accesed on 2014 Jan 07].

16. Brasil. Ministério da Saúde. Secretaria de Atenção à Saúde. Secretaria de Vigilância em Saúde. SB Brasil 2010: Pesquisa Nacional de Saúde Bucal: resultados principais / Ministério da Saúde. Secretaria de Atenção à Saúde. Secretaria de Vigilância em Saúde. - Brasília Ministério da Saúde, 2012.

17. Borrell LN, Papapanou PN. Analytical epidemiology of periodontitis. J Clin Periodontol 2005;32 Suppl 6:132-58

18. Kumaresan D, Balasundaram A, Naik VK, Appukuttan DP. Gingival crevicular fluid periostin levels in chronic periodontitis patients following nonsurgical periodontal treatment with low-level laser therapy. Eur J Dent 2016;10:546-50. 